\title{
Incorporating the Natural Environment in CoRporate Strategy: A Stakeholder Approach
}

\author{
Michael Jay Polonsky \\ University Of Newcastle \\ Newcastle, Australia
}

\begin{abstract}
Developing corporate strategies dealing with the natural environment requires that the organisation take into consideration a number of internal and external stakeholders. Whilst most firms understand this need, most do not have a process for examining the relevant stakeholders and including them in the environmental strategy development process. This paper discusses how firms can use the stakeholder management process to identify important environmental stakeholders. It also discusses how firms can use an expanded version of the stakeholder strategy matrix to incorporate stakeholders into the environmental strategy development process. Utilising these tools would allow firms to develop more effective strategies to deal with the natural environment, thus reducing their vulnerability to external shocks caused by "unsatisfied" stakeholders.
\end{abstract}

\section{Introduction}

The growing importance of the firm's interaction with the natural environment has received an increasing amount of interest in the academic and practitioner press. For example, one study of the top $50 \mathrm{UK}$ organisations reported that $78 \%$ of Chief Executive Officers (CEO) believed green issues were important to organisations' present activities, $82 \%$ indicated that green issues would be important in the future [Peattie and Ring 1993]. In attempting to develop strategies to address the firm-natural environment interface, firms need to realise they are responsible to numerous internal and external stakeholder groups [Winter and Legerwood 1994]. A broad range of groups' are pressuring firms to behave in a more environmentally "responsible" fashion, these include: consumers [Ottman 1993, Vandermere and Oliff 1991, Vaughan et. al. 1994]; governmental bodies [Spearot 1991, Davis 1992]; competitors [Shearer 1990, Taylor 1992, McDaniel and Rylander 1993]; environmental groups [Anonymous 1991, Westley and Vredenburg 1991]; and shareholders [Copulsky 1991, Thomlison 1992]. Given that stakeholder group's often have competing objectives, completely satisfying all stakeholders with one set of environmental strategies may be difficult, if not impossible [Lerner and Fryxell 1994]. In many cases achieving one group's objectives will result in another group being disappointed. Therefore any strategic process that reduces conflict between the organisation and its stakeholders would be 
extremely beneficial, one such strategic process is the stakeholder management process.

There is extensive management literature examining stakeholder theory [Donaldson and Preston 1995, Lerner and Fryxell 1994, The Toronto Conference 1994]. Though the stakeholder management process can be used as a strategic planning tool to incorporate the concerns of stakeholders in relation to any strategic issue, there has been little examination as to how stakeholders can be or have been integrated into corporate environmental strategy development, or any strategy development process for that matter. There are some examples in the literature relating to strategies that can be used to include stakeholders in specific situations [Aggarwal and Chandra 1990, Maranville 1989], though these papers fail to develop a generalisable stakeholder process.

This paper will attempt to address the issue of how organisations can integrate stakeholders into corporate strategy dealing with the natural environmental (hereafter identified as corporate environmental strategy). While the same basic process can be applied to other strategic issues, it could be argued that few other issues involve the same degree of involvement from such a diverse range of stakeholders. Therefore the stakeholder management process is especially relevant to corporate environmental strategy.

The paper is divided into two sections: the first provides a brief overview of stakeholder theory and the stakeholder management process; the second examines the literature on how stakeholders can be integrated into the strategy development process, and the implications of using stakeholder management in designing corporate environmental strategy. Further, the second section builds on the limited literature examining the stakeholder strategy matrix. This literature and the matrix are expanded by incorporating a broader range of "influencers" or "bridging" groups in the strategy process. Examples of how environmental stakeholders have been integrated into firms' environmental strategy and the corporate environmental strategy formulation process are included throughout the paper.

\section{An Overview Of Stakeholder Theory}

According to Freeman, in 1964 the Stanford Research Institute defined stakeholders as "those groups without whose support the organisation would cease to exist". As more researchers have examined stakeholder theory the number of definitions have proliferated. No consistent definition appears in the literature, with many authors taking slightly different perspectives as to which groups can be identified as stakeholders [Clarkson 1994a \& b, Donaldson and Preston 1995, The Toronto Conference 1994]. The difference in perspectives is based on a difference of opinion as to which groups have a "stake" in organisational activities. One of the more widely accepted definitions of a stakeholder is based on the principle that " $(\mathrm{T})$ he firm takes into account all of those groups and individuals that can affect, or are affected by, the accomplishment of organisational purpose" 
[Freeman 1984]. Thus the firm is required to "take into account its relationship with specific stakeholder groups as it sets corporate direction and formulates its strategies" [Roberts and King 1989]. Using this view the stakeholder can be identified as almost any group remotely involved in organisational activities. An alternative perspective suggested by Clarkson is that "All Stakeholders bear some form of risk" [Clarkson 1994b]. Thus in Clarkson's narrower definition some stakeholders, such as the media who do not bear "risk" in the firm-stakeholder interface, might be omitted. In this paper Freeman's broader definition of a stakeholder will be used. Given the experts inability to develop a comprehensive definition [Clarkson 1994a] no attempt will be made to further examine this issue here, but it may be one area warranting further research.

The stakeholder management process, as well documented by Freeman and others, is one tool designed to allow the firm to modify strategy to reflect the concerns of their various stakeholders, and is applicable to corporate environmental strategy. As defined in the literature this process comprises four basic stcps: 1) identify the relevant stakeholder groups in relation to the issue being addressed; 2) determine the stake and importance of each stakeholder group; 3) determine how effectively the "needs" or "expectations" of each group is presently being met; and 4) modify corporate objectives and priorities to take into consideration stakeholder interests [Freeman 1984, Carroll 1989, Roberts and King 1990]. While the focus of this paper is examining how stakeholders can be integrated into the environmental policy development process, it is important to understand this general four-step stakeholder management process.

\section{Step One: Stakeholder Identification}

The first step in the stakeholder management process is to identify which organisations or individuals are environmental stakeholders. Stakeholders may differ for each specific issue examined by the firm and may vary across firms [Freeman 1984]. When evaluating green marketing strategies it has been suggested that activities such as product development, promotional mix, support services, manufacturing and production processes, $R \& D$, material purchasing and waste disposal activities all need to be considered when determining stakeholders [Vandermere and Oliff 1990].

Firms should attempt to include "any person or organisation with a vested interest in the outcome of a companies environmental effort" [Thomlison 1992]. Thus the firm must concern itself will all groups, internal and external, which are affected by the firms environmental behaviour or who can influence the firm's environmental behaviour. For example consumers may demand products have various environmental attributes, regulators may require corporate compliance with specific environmental standards, or unions may "protest" over questionable corporate environmental practices.

The identification of all stakeholders is essential for the remainder of the process to be effective. It is therefore necessary to utilise some type of systematic approach to determine who the relevant stakeholders are. While no general 
process has been accepted in the literature, stakeholder audits are one process that firms can use to identify all appropriate stakeholders (See Freeman 1984 for a more detailed discussion of this process.)

Once the firm identifies all of the appropriate stakeholders it can then develop a stakeholder map. This map visually identifies the relationships between the stakeholders and the firm, it also identifies the relationships among stakeholders. When identifying stakeholders it needs to be realised that individuals often have several different roles at any one time. For example, employees may consume the firm's products, live in the local community, own shares in the firm, and be a member of a special interest group. This issue is extremely important, for each firm may face a different set of stakeholders in relation to a given issue. Thus developing a "generalisable" stakeholder map in relation to all firms' environmental strategies, may be impossible.

\section{Step Two: Determining the Stakes}

The firm must determine each stakeholder's "stake" in respect of the issue being examined. Each group's "stake" varies by issue and firm, thus one group might have a "high" stake in one firm's environmental policy and a low stake in another. For example, stakeholders "concerned" about deforestation may be more "influential" in relation to logging firms' activities, yet may have a negligible influence on the chemical industry. An individual's stake is his/her potential or ability to influence the firm's behaviour. It should be noted that stakeholders can have both a positive and/or a negative "influence" on organisational outcomes [Freeman 1984, Savage et al 1991]. Firms have been traditionally more concerned about stakeholder's potential for harm, rather than his/her potential for cooperation. This point has significant implications in relation to environmental strategy development and is a focus of the strategy development matrix. A number of other ways can be used to categorize stakeholders: position [The Toronto Conference 1994], interest [Freeman 1984], power [Freeman 1984], risk [Clarkson 1994b] and formality [Savage et al 1991]. However, an in-depth discussion of these classifications will not be undertaken in this paper.

Stakeholders can also have a direct influence or indirect influence on firm's behaviour. In the case of a direct influence a given group's behaviour directly "modifies" organisational outcomes. For example, consumers boycotting producers of "environmentally harmful" products result in lower corporate profits. Stakeholders' indirect influence on organisational behaviour occurs were there is a chain of events affecting the firm's behaviour. For example, local residents may be concerned about the environmental impact of a new manufacturing plant in their community and petition their local council not to grant the firm a building permit. If the council bows to community pressure, the firm will have to find an alternate location.

The completion of Step Two (as well as Step Three discussed below) is very difficult without open communication channels between the organisation and the stakeholder group. Unfortunately, in many situations organisations may not be on 
favourable terms with all stakeholders. In these situations the firm will have to develop communication channels if stakes are to be accurately determined. (Specific strategies to develop communication channels, such as bridging stakeholders, will be discussed later in the paper.) $\mathrm{A}$ less desirable alternative may be to "estimate" the stakes of the groups and how well they are met.

Even in situations where communication channels do exist, not all stakeholder groups have clearly established policy statements. indicating their expectations or needs in relation to a specific environmental issue. In addition, to say that every stakeholder group is made up of homogeneous individuals would be an exaggeration. For example, there are many regulatory bodies that license different aspects of a firm's environmental behaviour. Therefore the firm needs to identify stakeholders in "identifiable units" that have a common set of objectives.

\section{Step Three: Determine how well expectations are met}

Determining if there is a gap between expectations and performance is an important step in the stakeholder management process. The expectations of stakeholders may be difficult to assess, for as was discussed in Step Two, the firm may not be able to freely communicate with stakeholders, stakeholder groups may not have clearly established objectives, or groups may be very heterogeneous.

Where the firm's environmental behaviour does not at least match stakeholders' expectations, a gap will exist. This gap results in stakeholders being dissatisfied with the firm's present environmental behaviour, with the size of the gap indicating the degree of stakeholder dissatisfaction. If there is no gap, stakeholders would be satisfied with firm's environmental behaviour.

\section{Step Four: Adjusting Strategy}

The last step of the stakeholder management process is the readjustment of corporate priorities to bring the firm in line with stakeholders interests" [Roberts and King 1989]. This readjustment requires that the proceeding three steps have been undertaken appropriately, for if not, the firm's new strategy may not reduce the gap in stakeholders' expectations and corporate behaviour.

Modifying environmental strategy simply to address the needs of one "unsatisfied" stakeholder may result in the alienation of other stakeholders who are already "satisfied" with the firm's performance. For example, incorporating a new technologically advanced production process that reduces pollution may satisfy local community concerns, but the reduction in profits due to increased capital costs may be of concern to owners. In addition, if the new technology displaces workers, unions may also be concerned. As this example highlights, environmental activities can have complex implications for stakeholders. The firm needs to consider all implications of a shift in strategy, not simply the effect on a specific stakeholder group.

A reduction in the gap between expectations and behaviour can occur for one of three reasons: 1) the firm's behaviour changes, such that it is closer to stakeholder expectations; 2) stakeholder expectations change and become more ac- 
cepting of existing corporate behaviour; or 3) both stakeholders' expectations and organisational behaviour change. In most situations a change will result due to a movement by both parties, with a "change" in stakeholder expectations possibly occurring due to a change in corporate behaviour. For example, if the firm develops more credible and accurate communication channels, stakeholders may modify their expectations of corporate activity.

Even after a change in strategy has occurred a gap may still exist, thus the potential for negative stakeholder behaviour may be reduced. In these cases the firm will be able to develop contingency programs to address the potential negative behaviour that may arise from dissatisfied stakeholders. Thus the stakeholder management process allows the firm to address the environmental needs of stakeholders or develop strategies for problems should they arise.

\section{Integrating Stakeholders Into Environmental Strategy Development}

The objective of the four step process described above, is to enable the firm to modify corporate environmental strategy such that "all" stakeholders' objectives are considered. While this is an important objective, the stakeholder management process alone, does not give managers sufficient clues as to how stakeholders should be integrated into the strategy formulation process. Furthermore it is unclear from the four step stakeholder management process, which stakeholders should be included in strategy development. Is it simply appropriate to target stakeholders who are most affected by firms' activity or would it be better to focus on stakeholders who have the ability to affect firms' ultimate performance? An alternative strategy might be to integrate stakeholders who have the greatest influence on "other" stakeholder groups. The focus of this section of the paper is to examine the issue of incorporating stakeholders in the strategic process in more detail.

It should be recognised that it is highly unlikely that all stakeholder's expectations will be met. Therefore, the firm must somehow ascertain which stakeholder's should be incorporated. Since stakeholders have the ability to positively or negatively influence the firm [Freeman 1984, Savage et. al. 1991], integrating the right group is essential. Specific organisational strategies to integrate stakeholders will differ, depending on the issue and the groups potential to cooperate or threaten the firm's performance.

While Freeman's [1986] text addresses the issue of including stakeholders in the strategic process, little other academic literature examines this issue. Of this literature, most focuses on methods for evaluating stakeholders' importance [Roberts and King 1989, Ryan 1992] or methods of determining the rewards of adopting a stakeholder orientation [Barton et. al. 1989, Lerner and Fryxell 1994, Preston and Sapienza 1990]. There is very little literature examining specific strategies that can be used to incorporate stakeholders into the strategic development process [Freeman 1984, Maranville 1989, Savage et al 1992]. 


\section{The Stakeholder Strategy Matrix}

A matrix approach has been suggested in the literature as one method that could be used by the firm to determine the appropriate strategy for addressing different types of stakeholders [Freeman 1984, Savage et. al. 1991]. The stakeholders identified in Step One of the stakeholder management process would be incorporated into the suggested matrix (see Figure One). The underlying issue, as identified by Freeman (1984) and Savage et al (1991), is to identify stakeholders' ability to cooperate with the firm (i.e., assist it in achieving its objectives) or their ability to threaten the firm's performance (i.e., harm it in achieving its objectives). It might be suggested that cooperation and threatening behaviour are extremes of one continuum, but this is not necessarily the case. In developing strategy a firm needs to consider that each stakeholder has the ability both to threaten and to cooperate. The objective of corporate strategy is to reduce the threatening potential and increase the cooperative behaviour. Thus the potential to cooperate and to threaten are the two characteristics placed on the two axes of the matrix. Each stakeholder's position would have been partially determined in Step Two of the stakeholder management process.

Figure One

The Traditional Stakeholder Strategy Matrix

\begin{tabular}{|c|c|c|}
\hline & \multicolumn{2}{|c|}{$\begin{array}{l}\text { Stakeholders Potential to Threaten the } \\
\text { Organisation }\end{array}$} \\
\hline & High & Low \\
\hline Stakeholders & $\begin{array}{l}\text { Collaborate with the } \\
\text { Stakeholder } \\
\text { (1) }\end{array}$ & $\begin{array}{l}\text { Involve the Stakeholder } \\
\text { (2) }\end{array}$ \\
\hline $\begin{array}{l}\text { Poltential to } \\
\text { Cooperate With } \\
\text { the Organisation }\end{array}$ & $\begin{array}{l}\text { Defend against } \\
\text { Stakeholders actions } \\
\text { (3) }\end{array}$ & $\begin{array}{l}\text { Monitor for changes } \\
\text { (4) }\end{array}$ \\
\hline
\end{tabular}

In earlier works both Freeman (1984) and Savage et. al .(1991), also put forward a generic set of strategies that the firm can use to address each type of stakeholder (See Table One). Freeman identified that stakeholders can have a positive or negative influence on firm activities, whereas Savage et al concentrated on stakeholders potential to influence organisational behaviour negatively. It is important to realise that the stakeholders potential to act and their willingness to act are not directly related. An environmental group may have the ability to cooperate with an organisation, but they may not be willing to do so. Therefore when looking at strategies it is important to examine not only strategies addressing 
Table One

Generic Stakeholder Strategies

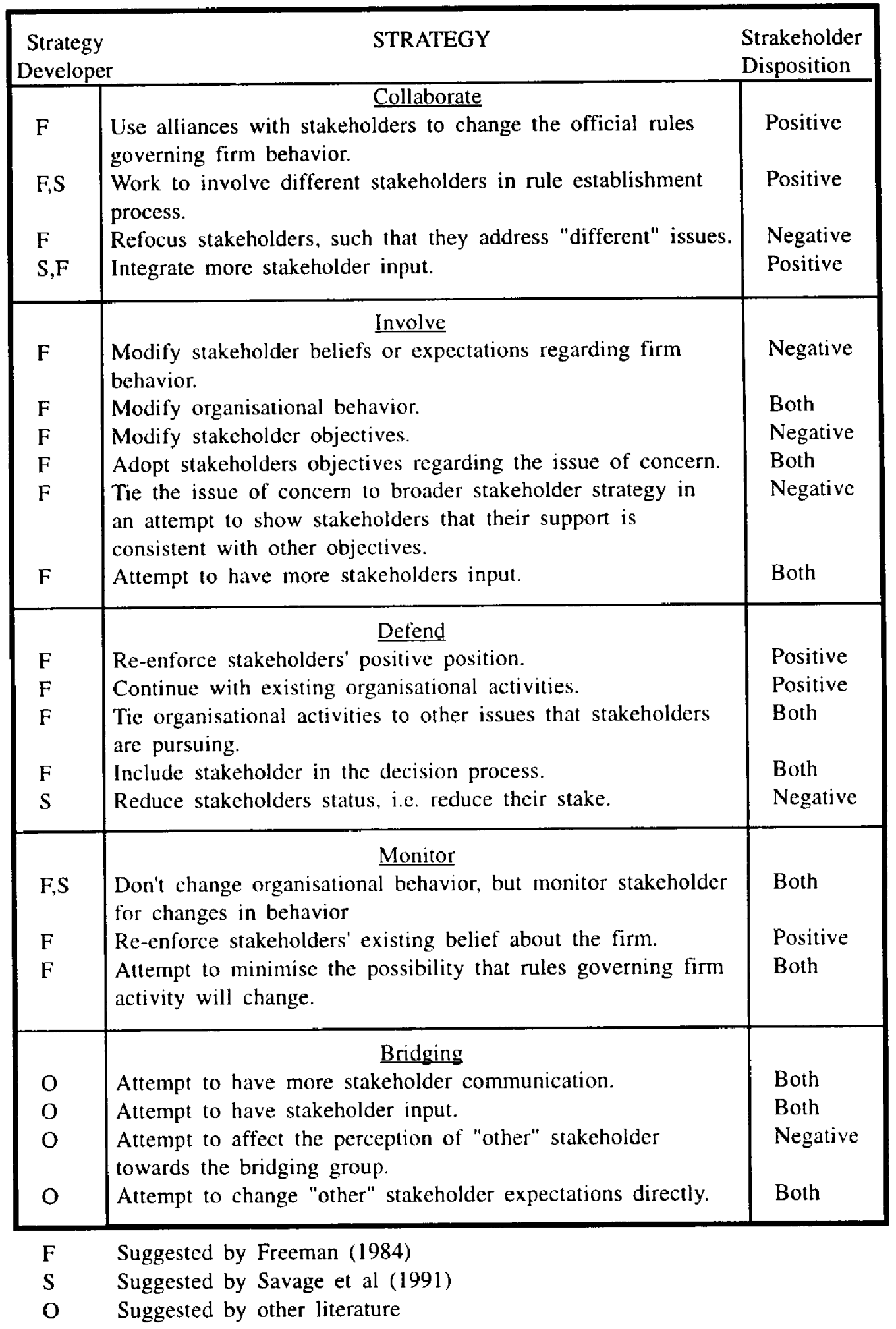


stakeholders who are positively disposed towards an organisation but those who are negatively disposed towards an organisation as well. Some strategies may only be appropriate for a stakeholder with a specific disposition towards the organisation, i.e., Positive or Negative. In other cases a given strategy may be appropriate for either type of stakeholder, i.e. Both.

While the classification of stakeholders using cooperation and threatening behaviour is useful, it only refers to the stakeholder-firm interface, omitting the important stakeholder-stakeholder relationship. As suggested earlier the interaction between stakeholders can have a significant indirect impact on corporate environmental behaviour. The importance of these interactions have been identified by several authors, who have recognised the importance of "boundary spanners" or "bridging" groups [Brickner 1993, Feyerherm 1994, Mendleson and Polonsky 1995, Sharma et al 1994, Westley and Vredenburg 1991]. These groups act as influencers in the stakeholder process, indirectly affecting organisational activities. One definition of the term "bridging stakeholder" could be all "groups who forward their own ends as well as to serve as links" between other stakeholders [Westley and Vredenburg 1991].

Bridging groups can also be classified as stakeholders in their own right under the broader definition of a stakeholder as "all of those groups and individuals that can affect, or are affected by, the accomplishment of organisational purpose" [Freeman 1984]. The stakeholder matrix presented in Figure One does not allow for these influencers and needs to be modified to take into consideration the role of bridging stakeholders. As these groups can fall within any of the four quadrants, in their own right, the bridging classification must overlap all four of the traditional quadrants established by earlier authors. Figure Two incorporates this additional "bridging" category into the traditional matrix (Figure One) and additional generic strategies are incorporated at the bottom of Table One.

\section{Figure Two \\ Modified Stakeholder Strategy Matix}

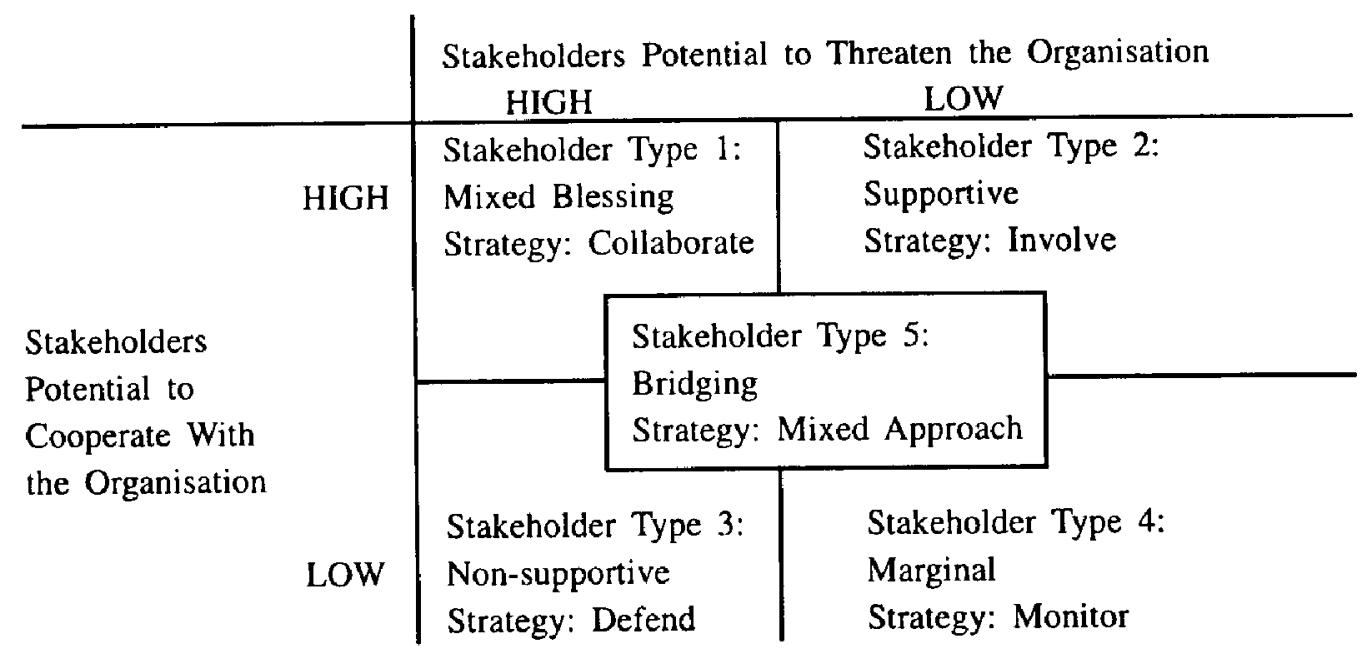




\section{Classifying Stakeholders}

At first examination the classification of a stakeholder group into Figure Two may appear a simple matter. Yet when classifying stakeholders, it is important for managers to consider all potential interactions between the organisation and their stakeholder, not simply the interactions as they exist today. For example, it is likely that most firms consider regulatory bodies as a non-supportive stakeholder and adopt a defensive strategy for dealing with them (See Table One and Figure Two). Yet using innovative strategies other firms may consider these stakeholders to be Type 1, Mixed-Blessing stakeholders and form collaborative relationships with them. This type of relationship occurred when regulatory bodies developed environmental marketing guidelines in the US and Australia [Kangun and Polonsky 1995]. Several businesses made submissions to their respective regulatory bodies, requesting that the regulators establish concise guidelines controlling environmental marketing activities. These firms went on to suggest specific issues that they believed needed to be addressed [FTC 1991, NAAG 1990, TPC 1990]. In this case the organisations collaborated with regulators to establish new environmental marketing guidelines, whereas other organisations might have perceived regulators as adversaries and adopted a confrontational strategy. Thus organisations must not simply consider present probable strategies. They must also consider all potential strategies available before classifying stakeholders into a specific quadrant.

As can be seen in Table One there are several different strategies for stakeholders in each quadrant, these strategies have been suggested by Freeman (1984) and Savage et al (1991), as well as in the literature relating to bridging stakeholders. Each strategy is not mutually exclusive, some are appropriate for more than one type of stakeholder group. Implementation of each strategy may be extremely difficult as well, especially those designed to deal with Bridging stakeholders.

These general comments about classifying stakeholders and utilising strategies form the backdrop for an examination of the five stakeholder types. A discussion of these classifications and appropriate strategies follows.

\section{Mixed Blessing}

These stakeholders are extremely important, for they have the ability to cooperate with the organisation or threaten the achievement of organisational objectives. One such environmental stakeholder might be the firm's employees. It is this group that ultimately determines a firms' environmental performance by complying or not complying with specific operational or environmental procedures. When employees do not comply with environmental policies, "environmental breaches" may occur. These individual "errors" or "omissions" are ultimately the responsibility of the firm. For example, the Exxon Valdese disaster, partially caused by the operating breaches of the pilot on duty at the time, left Exxon with a billion-dollar bill, extensive negative publicity, and a loss of consumer good- 
will. In another example, a firm may wish to update a production process to reduce environmentally harmful emissions of some type. If this new process affects staffing requirements, the firm will need the support of workers and unions if the new process is to be successfully implemented.

As suggested by Figure Two and Table One, one appropriate strategy for Mixed Blessing stakeholders is to integrate them into the strategy development process. This action will ensure that the objectives of the stakeholders are included in strategy as it is formed and thus will not require a later "redevelopment" of strategy. One innovative example of a collaborative strategy occurred between the Australian firm $\mathrm{ACI}$ and the environmental group, the Australian Conservation Foundation (ACF) [Mendleson 1994]. ACI wanted to develop a food packaging that would allow them to use recycled plastic, which had not been previously permitted due to health concerns. To tackle this problem ACI collaborated with the ACF. The result was in a new multilayer PET plastic that allowed recycled plastic to be used for drink and food containers by placing a layer of virgin plastic between the food and the recycled plastic [Mendleson 1994]. Previously environmental groups had been "pressuring" producers to reduce PET use. Thus ACI turned a normally "hostile" environmental stakeholder, into an ally. A collaborative strategy minimised the potential for threatening behaviour from ACF and increased its cooperative behaviour.

\section{Supportive}

These stakeholders have the ability to cooperate with the firm, but have little ability to threaten organisational activities. One such environmental stakeholder might be a firm's suppliers. For example, when McDonald's decided to reduce its impact on the natural environment, it instituted a number of recycling programs relating both to disposal of waste and to purchase of recycled materials. This strategy greatly assisted the suppliers of recycled plastics and polystyrene, as they now had a quality source of material to recycle, as well as a consumer for goods made from their recycled materials [Hume 1991, Gifford 1991].

Freeman (1984) and Savage et. al. (1991), disagree on appropriate involvement strategies for Supportive stakeholders. This disagreement is due to Savage et. al. (1991) not considering the possibility of negatively disposed groups' having little negative impact but high cooperative potential. These cases may require extremely innovative strategies to be developed in order to effectively diffuse negatively disposed stakeholders. For example, when the International Olympic Committee requested that all future Olympic bids integrate environmental principles the Sydney Olympic Committee established their environmental guidelines together with Greenpeace [Sydney 2000 1993a]. This involvement resulted in the Sydney bid being the most environmentally responsible [Sydney 2000 1993b, Sydney 2000 1994] and may have assisted in Sydney's winning the Olympics for the year 2000. Thus by involving Greenpeace, the Sydney Bid Committee adopted stakeholder's objectives, had more stakeholder input, modified organisational behaviour, and may have even modified stakeholders' beliefs about the organisation. 


\section{Non-supportive}

These stakeholders have the ability to threaten organisational activities, but have little ability to cooperate with the organisation. As mentioned earlier governmental bodies are often considered to be Non-supportive stakeholders. They establish environmental regulations and guidelines that many firms believe are restrictive. This is not always the case, for there are numerous examples of where organisations have cooperated with regulatory bodies in establishing various environmental guidelines. As suggested earlier one such example, is the establishment of environmental marketing regulations, both in the US and Australia [FTC 1991, Kangun and Polonsky 1995, NAAG 1990, TPC 1990]. In both these cases various organisations suggested that regulations were needed to allow consumers to make informed purchasing decisions and to protect competition. Yet, none of the firms suggested that regulating environmental marketing claims would assist in protecting the environment. In this example, organisations tied their activities to stakeholders' (regulatory bodies) other objectives.

\section{Marginal}

These stakeholders have little ability to threaten organisational activities or to cooperate with the organisation. This group may have little interest in the firm's environmental activities at a given point in time. But this interest may change over time and therefore the potential for cooperation or threat may change. For the purposes of an example, it is useful to examine how the relationship between financial institutions and organisations changed between the 1970 s and the 1980s. In the 1970s when financial institutions loaned firms capital they were concerned with the return on their investment, few banks had any concern for the borrowing organisation's environmental activities. This relationship changed in the 1980's after various US court rulings on the Superfund Act of 1980 [Hector, 1992]. The Act held banks ultimately liable for their customer's pollution. This law shifted the burden of paying for environmental cleanups from the government to the owners, past and present, of polluted property [Sarkin and Schelkin 1991].

To address financial institutions new "interest" in their client's environmental activities, firms had to keep rigid environmental records and undertake regular environmental audits [Quirke 1992]. Those organisations monitoring financial stakeholders and the business environment would have observed the movement of these Marginal stakeholders to the Non-supportive category. If this were the case, they may have anticipated the change in stakeholder concern and adjusted their environmental strategy accordingly. Those firms who did not anticipate the shift, may have had significant difficulty in obtaining financing until their environmental strategy changed. An unrevised strategy may also have put them at a competitive disadvantage to those firms who anticipated the change in stakeholder interest and acted accordingly. 


\section{Bridging}

As suggested earlier, Bridging stakeholders are not directly referred to in the stakeholder strategy matrix literature. As suggested in Figure Two Bridging stakeholders fit into one of the four classifications identified earlier, and they also influence "other" stakeholder groups' expectations and behaviour towards the firm. The influencing or bridging role may be more important than the stakeholders direct affect on the firm. There may be many important Bridging stakeholders that need to be carefully watched. For example, a financial institution's role as a Marginal stakeholder was shifted to that of a Non-supportive stakeholder. This shift was the result of "interference" from a Bridging stakeholder, legislators, who initiated the Superfund Act.

Another example of a Bridging stakeholder is the media. They may only influence organisational behaviour through their bridging role and have no direct influence on the organisation, i.e., they could be classified as a Marginal stakeholder as well. The media influences other stakeholders through the "publicising" of a variety of activities, such as the forcible removal of environmental protesters from an organisations facilities, or the occurence of an environmental accident. While the media itself does not directly influence the firm's behaviour, they may impact a number of stakeholders who can, such as consumers, regulators, employees, and shareholders who can exert influence.

Strategies designed to address Bridging stakeholders are more complex than those of the other four groups. The firm must identify in which of the four quadrants the stakeholder falls, as well as identify which stakeholders can be affected by a Bridging group and how important that Bridging groups influence might be. One of the positive strategy approaches is to have open communication channels with the Bridging stakeholders. This strategy allows organisations to "influence" the Bridging group's actions and thereby indirectly to affect the "influenced" groups' expectations or behaviour towards the firm.

For example, an organisation that has a good relationship with the media may be able to ensure that a balanced perspective is presented and that stories are not presented in a sensationalist fashion. This approach would reduce the negative influence of the media's Bridging role on other stakeholders. A more aggressive strategy might be to target the influenced stakeholders directly and to seek to minimise the Bridging groups' effect. To accomplish this, the firm could attempt to increase the validity of the firm-based information (i.e., change stakeholder expectations towards the firm) or it could attempt to minimise the credibility of the Bridging stakeholder (i.e. change stakeholder expectations towards the Bridging group).

\section{Implications and Conclusions}

Through the use of the stakeholder management process and the associated stakeholder strategy matrix, the firm can include stakeholders into the environmental strategy development process. This inclusion should ensure that the firms 
environmental strategies address the needs and expectations of its various stakeholders. This process requires managers to consider stakeholders in an innovative light, for not only is the present relationship between the firm and stakeholders important, but so are future activities and interactions. Thus shifting stakeholders between quadrants within the strategy matrix, or designing strategies that maximise organisational benefit, requires that managers think of potential methods of building "links" between the firm and their stakeholders. To some extent all strategies suggested require some degree of socialising stakeholders into the organisational decision making process. This socialisation can range from the extreme of collaborative activities, to a minimalist approach of developing simple "formal" communication that would feed into the organisation's management information system.

One of the main strategies the firm must utilise is continual monitoring of stakeholders. This process should determine how their stakes "change" as well as to determine how effectively the "needs" or "expectations" of each group are being met. In other words firms may need to continually undertake Step Two and Step Three in the stakeholder management process to ensure that strategies are effective.

Developing good communication channels between the firm and its stakeholders, is one effective corporate strategy. However, if the information obtained is not incorporated into the firm's management information system and used when developing environmental strategy, the firm is not maximising the value of its communication with stakeholders. Information is more than a simple monitoring device, it is also an important strategy tool.

In those cases where stakeholders are not open to communication due to their negative disposition towards the firm, alternative strategies need to be developed. These strategies may attempt to change the stakeholder group's disposition, or minimise its negativity. Strategies to undertake this "change" may require the use of Bridging stakeholders to "communicate" on behalf of the firm with these negatively disposed stakeholders. In cases where stakeholders' expectations cannot be met or changed, the firm will be able to develop contingency programs to minimise any potential harm.

Bridging stakeholders may be one strategy tool that can be effectively utilised by organisations. Numerous examples in this paper demonstrate how the inclusion of an independent stakeholder in environmental strategy has led other stakeholders to modify their behaviour and expectations. These changes can occur in either a positive or negative fashion. As a positive example, some firms have formed strategic alliances with environmental groups to develop new products, which are perceived by consumers to be more environmentally responsible. Thus environmental groups have played an important Bridging role as well as being a Mixed Blessing type of stakeholder However, bridging stakeholders have to be used carefully, for they may also send the "wrong" message to other stakeholders [Mendleson and Polonsky 1995]. As a negative example, involving "radical" environmental groups in firm activities may alienate a "conservative" general pub- 
lic, rather than put them more on side. In addition if Bridging groups are perceived to lose their "objectivity" the benefits of their involvement may be lost [Carson and Fyfe 1992, Westley and Vredenburg 1991].

While innovative strategies appear to be a useful method of incorporating stakeholders into the environmental strategy development process, more research needs to be undertaken into the successfulness of the various strategies. The literature presented does provide some interesting case studies, but extensive opportunities exist for additional quantitative and qualitative research in this area. Research needs to examine the effectiveness of the various generic strategies for each of the five different groups. More research could be undertaken with Bridging stakeholders to determine how they can be motivated to become involved with the firm or to examine the potential loss of credibility caused by a "closer" Bridging group-firm relationship. In addition more research might be done regarding the specific organisational structures required for socialising stakeholders, as a variety of approaches may be possible. The structures established might determine the effectiveness of the specific strategies, with some structures being more appropriate for a given strategy.

\section{References}

Aggarwal, Raj and Chandra, Gybe, "Stakeholder Management Opportunities and Challenges", Business, Vol 40 No 1 (1990): 48-51.

Anonymous, "Spurts and Starts: Corporate Role in '90s Environmentalism Hardly Consistent" Advertising Age, Vol. 62 Nc 46 (Oct. 28,1991): GR14-GR16.

Barton, Sidney L., Ned C. Hill, and Srinivasan Sundaram, "An Empirical Test of Stakeholder Theory Predictions of Capital Structure", Journal of Financial Management, Vol 18 No 1 (1989): 36-44.

Brickner, Wm Scott, "Stakeholders versus Constituents: What Stakeholder Theory Tells Us About the Organization and Reform of Congress \& What Congressional Reform Tells Us About Stakeholder Theory" Proceedings 5th annual IABS Conference, (1993): 199-204.

Carroll, A. B., Business and Society - Ethics and Stakeholder Management, Cincinnati Ohio USA, South-Western Publishing Company, 1989.

Carson, Patrick and Andrew Fyfe, "A Canadian Retailers Perspective: Loblaw Companies Ltd." in Martin Charter (ed) Greener Marketing Sheffield, England, Greenleaf Publishing, (1992): 307-310.

Clarkson, Max "Report of the Definitions Working Group." Proceedings of the Second Toronto Conference on Stakeholder Theory, 1994a.

Clarkson, Max "A Risk Based Model of Stakeholder Theory" Proceedings of the Second Toronto Conference on Stakeholder Theory, 1994b. 
Copulsky, William, "Balancing the Needs of Consumers and Shareholders" The Journal of Business Strategy, Vol 12 No 6 (1991): 44-47.

Davis, Joel J., "Ethics and Environmental Marketing." Journal of Business Ethics, Vol 11 No 2, (1992): 81-87.

Donaldson, Thomas and Lee E. Preston, "The Stakeholder Theory of the Corporation: Concepts, Evidence, Implications." Academy of Management Review, Vol 20 No 1 (1995): 65-91.

Federal Trade Commission, Hearings on Environmental Marketing Issues, Washington, DC USA: FTC, July $17-18,1991$.

Feyerherm, Ann E. "The Influence of Dialogue on Multiple Stakeholders in Interorganizational, Collaborative Networks." Proceedings 5th annual IABS Conference. (1994): 517-528.

Freeman, R. Edward, Strategic Management: A Stakeholder Approach, Pitman Publishing Company, Massachusettts, 1984.

Gifford B., (1991) "The Greening of the Golden Arches- McDonalds Teams With Environmental Group to Cut Waste". The San Diego Union, (August, 19, 1991): C1,C4.

Hector, Gary., A New Reason You Can't Get a Loan. Fortune, Vol 126 No 6 (1992): 107-112.

Hume, Scott, "McDonald's: Case Study" Advertising Age, Vol 62 No 5 (1991): 32.

Kangun, Norman and Michael Polonsky, "Regulation of Environmental Marketing Claims: A Comparative Perspective" International Journal of Advertising, Vol 14 No 1 (1995): 1-24.

Lerner, Linda D. and Gerald Fryxell, "CEO Stakeholder Attitudes and Corporate Social Activity in Fortune 500." Business and Society, Vol 33 No 1 (1994): 58-81.

Maranville, Steven J., "You Can't Make Steel Without Having Some Smoke: A Case Study in Stakeholder Analysis" Journal of Business Ethics, Vol 8 No 1 (1989): 57-63.

McDaniel, Stephen W. and David H Rylander, "Strategic Green Marketing." Journal of Consumer Marketing, Vol 10 No 3 (1993): 4-10.

Mendleson, Nicola, "Environmental Marketing Business Partnering at AFC- Developing Strategic Alliances." Environmental Marketing: Critical Success Strategies for Reaching the Green Consumer Proceedings of the 1994 Conference, (February, 1994): 87-103.

Mendleson, Nicola and Michael Jay Polonsky "Using Strategic Alliances to Develop Credible Green Marketing" (With N. Mendleson) Journal of Consumer Marketing. Vol 12 No 2 (1995): 4-18. 
National Association of Attorneys-General, (NAAG) The Green Report: Findings and Preliminary Recommendations for Responsible Advertising. USA: National Association of Attorneys-General, 1990.

Ottman, Jacqueln, "Brand 'Stewards' Will Guide Environmental Planing" Marketing News, Vol 26 No 8 (1993): 15.

Peattie, Ken and Tony Ring "Greener Strategies: The Role of the Strategic Planner" Greener Management International Issue 3 (1993): 51-64.

Preston, Lee E. and Sapienza, Harry J., "Stakeholder Management and Corporate Performance", The Journal of Behavioral Economics, Vol 19 No 4 (1990): 361-375.

Quirke, Brendan, “Environmental Auditing: What's It All About?," Management Accounting, Vol: 70 No 3 (1992): 34-35.

Roberts, Nancy C. and King Paula J., "The Stakeholder Audit Goes Public" Qrganizational Dynamics, Vol 17 No 3 (1989) 63-79.

Ryan, Pratrick, "Calculating the "Stakes" for Corporate Stakeholders as Part of Business Decision-Making", Rutgers Law Review, Vol 44 No 3 (1992): 555-583.

Sarkin, D. and J. Schelkin, "Environmental Concerns and the Business of Banking," The Journal of Commercial Bank Lending, Vol 73 No 3 (1991): 7-19.

Savage, Grant T.; Nix, Timothy W.; Whitehead, Carlton J.; and Blair, John D., "Strategies for Assessing and Managing Organisational Stakeholders" Academy of Management Executive, Vol 5 No 2 (1991): 61-75.

Sharma, S., H. Vredenburg and F. Westley, "Strategic Bridging: A role for the Multinational Corporation in Third World Development", Journal of Applied Behavioral Science, Vol 30 No 4 (1994): 458-476.

Shearer, J.W., Business and the New Environmental Imperative. Business Quarterly, Vol 55 No 3 (1990): 48-52.

Spearot, Rebecca M., Environmental Liability: What You Don't Know Can Hurt You. Corporate Controller, Vol 4 No 1 (1991): 20-23.

Sydney 2000, Sydney 2000 Environmental Guidelines, Sydney Australia: Sydney 2000., 1995a.

Sydney 2000, Sydney's Olympic Village Plan Wins Support From Greenpeace, Sydney Australia: Sydney 2000, 1995b.

Sydney 2000, Environmental Guidelines for the Summer Olympic Games -Summary, Sydney Australia: Sydney 2000, 1994. 
Taylor, Stuart R., Green Management: The Next Competitive Weapon. Futures, Vol 24 No 7 (1992): 669-680.

TPC (Trade Practices Commission), Draft for Discussion Environmental Claims in Marketing, Canberra, Australia, Trade Practices Commission, 1990.

Thomlison, Bryan M., "Environmental Consumerism Must Meet Needs of Corporate Stakeholders" Marketing News, Vol 26 No 9 (1992): 12.

Vandermere, S. and Oliff, M.D., Consumers Drive Corporations Green. Long Range Planning, Vol 23 No 6 (1991): 10-16.

Vaughan, D.A.J., P. Scott and Craig Mickle, "Environment: What Do Europe's Boardrooms Think?" Greener Management International, Issue 7, (1994): 28-35.

Westley, Frances and Harrie Vredenburg, "Strategic Bridging: The Collaboration between Environmentalists and Business in the Marketing of Green Products" Journal of Applied Behavioral Science, Vol 27 No 1 (1991): 65-90.

Winter, Lynn and Grant Legerwood, "Motivation and Compliance in Environmental Performance for Small and Medium-Sized Business." Greener Management International, Issue 7, (1994): 62-72. 